\title{
The Relation between Perceived Social Support and Anxiety in Patients under Hemodialysis
}

\author{
Elham Davaridolatabadi ${ }^{1}$, Gholamhossein Abdeyazdan ${ }^{2}$
}

\begin{abstract}
${ }^{1}$ M.Sc. of Critical Care Nursing, Faculty member, Faculty of Nursing and Midwifery, Young Researchers and Elite Club, Isfahan (Khorasgan) Branch, Islamic Azad University, Isfahan, Iran

${ }^{2}$ M.Sc. Nursing, Faculty member, Faculty of Nursing and Midwifery, Isfahan (Khorasgan) Branch, Islamic Azad University, Isfahan, Iran
\end{abstract}

\section{Type of article: Original}

\begin{abstract}
Introduction: The increase in the number of patients under hemodialysis treatment is a universal problem. With regard to the fact that there have been few social-psychological studies conducted on patients under hemodialysis treatment, the current study was conducted to investigate anxiety and perceived social support and the relation between them among these patients.

Methods: This cross-sectional study was conducted on 126 patients under hemodialysis treatment in Isfahan in 2012. After randomly selecting a hospital with a hemodialysis ward, purposive sampling was conducted. Data collection tools included state-trait anxiety and perceived social support inventory. The data were analyzed using the Spearman correlation coefficient.

Results: Among the participants, $68.3 \%$ received average perceived social support. In addition, perceiving the tangible dimension of support was lower compared to other dimensions (Mean 40.02). Level of trait and state anxiety ( 65 and $67.5 \%$ ) of over half of the participants was average. There was in inverse relationship between state and trait anxiety and total perceived social support and emotional and information dimensions $(r=-0.340, r$ $=-0.229$ ). State and trait anxiety had the highest relation with emotional and information dimension of social support, respectively.

Conclusion: Patients under hemodialysis treatment suffer from numerous psychological and social problems. Low awareness and emotional problems result in the increase of anxiety and reduction of perceived social support. Reduction of social support has negative effect on treatment outcomes.

Keywords: hemodialysis; chronic renal failure; perceived social support; anxiety
\end{abstract}

\section{Introduction}

Chronic renal failure is very common around the world as a health problem (1). Outbreak of end-stage renal disease (ESRD) is increasing by $8 \%$ annually, while the increase in population is $1.3 \%$ (2). Usually, all patients with ESRD require replacement treatments, including hemodialysis, peritoneal dialysis, and kidney transplantation (3). With regard to the increase in the number of patients with ESRD, it is anticipated that the need for replacement treatments will increase significantly in later decades. In 2005, nearly 1.5 million patients with renal failure used replacement treatments (2). In fact, the number of patients under treatment is increasing (4) in such a way that, in 2005, it was anticipated that the number of patients in need of replacement renal treatments would double in the next decade. Hemodialysis, peritoneal dialysis, and kidney transplantation are replacement renal treatments, among which hemodialysis is the most common. About one million patients in the world are under hemodialysis treatment. Therefore, increase in the number of patients under hemodialysis treatment is a global problem (2). Patients under hemodialysis treatment suffer from different physical and mental problems (5) in such a way that for prevalence of depression is 10 to $30 \%$ in these patients (4). Among mood disorders, prevalence of anxiety is commonly observed

\section{Corresponding author:}

Elham Davaridolatabadi, Faculty of Nursing and Midwifery, Young Researchers and Elite Club, Isfahan (Khorasgan) Branch, Islamic Azad University, Isfahan, Iran.

Tel: +98.35354001, Fax: +98.35354065, Email: nurse.davari@yahoo.com

Received: May 20, 2015, Accepted: October 17, 2015, Published: March 2016

iThenticate screening: October 17, 2015, English editing: November 03, 2015, Quality control: February 02, 2016

(C) 2016 The Authors. This is an open access article under the terms of the Creative Commons Attribution-NonCommercialNoDerivs License, which permits use and distribution in any medium, provided the original work is properly cited, the use is non-commercial and no modifications or adaptations are made. 
in these patients (6). Anxiety in patients with ESRD is twice that of normal people in such a way that it is observed in $38 \%$ of these patients (4). Anxiety is related to poor health outcomes, including decrease of following medication regimen and quality of life and increase in hospitalization along with mortality and morbidity (4-7). Social interactions are very important in chronic patients, since these interactions have significant benefits for their health (8). Patients participating in social activities suffer from mental disorders to a lesser extent (8). Social support would reduce the risk factors of chronic diseases, including smoking, inactivity, and the change and maintenance of health behaviors (9). By increasing social support, stress reduces and cells and blood immune responses increase (8). Those people who access more social support can manage their stress better and experience better health outcomes (10). Studies show that social support is related to the quality of life in such a way that people who receive social support and are part of a larger social network enjoy a higher quality of life (11). However, people with lower social support face more challenges in coping with stress and are more vulnerable (10). In addition, reduction of social support increases the possibility of mortality (9). Social support is defined as a network of family, friends, and neighbors who are available when one requires mental, physical, or financial support (10). It includes emotional, tangible, and informational support (9). Support may be defined as perceived and received support. Perceived social support refers to the personal perception of access to support, while received support refers to the support that is practically received by individuals (10). There are two reasons for more recognition of mental-social aspects of patients under hemodialysis treatment, i.e., 1) increase in the number of these patients and 2) help to facilitate the application of therapies that increase quality of life (5). However, the number of studies conducted on mental-social aspects and their results on patients under hemodialysis treatment is limited (4). The current study was conducted to investigate anxiety and perceived social support in patients under hemodialysis treatment and to study the relation between these two variables in these patients.

\section{Material and Methods}

\subsection{Research Design and Setting}

This cross-sectional study is a descriptive-analytic study of correlation type conducted on patients under hemodialysis treatment in 2012 in Isfahan. The research environment in this study was all hospitals in Isfahan with hemodialysis wards. Research society was all the hemodialysis patients in Isfahan.

\subsection{Sampling and Eligibility Criteria}

With regard to the statistics available about hemodialysis patients in Isfahan in 2010 , for about 500 patients and considering the study power of $80 \%$, the least required sample size was obtained as 120 patients using the following formula (12): $\mathrm{n}=\left(\mathrm{Z}_{1-\alpha 2}+\mathrm{Z}_{1-\beta}\right)^{2}\left(\delta_{1}^{2}+\delta_{2}^{2}\right) /\left(\mu_{1}-\mu_{2}\right)^{2}=(1.96+0.84)^{2}(2662+2662) /(200)^{2}=119.6$. For sampling, first all hospitals in Isfahan with hemodialysis ward were selected (Alzahra, Zahraye Marzie, Shariati, Hojatiye and Khorshid hospitals); then they were numbered, and three numbers were selected randomly. These selected hospitals were Zahraye Marzie, Hojatiyeh, and Shariati hospitals. Then, purposive sampling was conducted according to the inclusion and exclusion criteria. The inclusion criteria in this study were 1) the ability to understand and speak Persian, 2) the desire to participate the study, 3) the ability to complete the questionnaire by the patient or with the help of a researcher, and 4) hemodialysis therapy two or three times a week and at least three months have passed from the first of hemodialysis treatment.

\subsection{Research Instrument and Statistical Analyses}

Data collection tools in this study included state-trait anxiety and perceived social support inventory. State-trait anxiety inventory consisted of two 20-question sections. The first section determines trait anxiety, and the second section determines state anxiety. Based on the answer to each one of 20 items in the above sections, a 1 to 4 scale score is allocated, and the total score of each one of the trait and state anxiety scales ranged between 20 and 80 . Depending on the acquired score in each section, the participant was classified in one of three groups, i.e., mild anxiety (20 to 39$)$, average anxiety (40 to 59 ), and severe anxiety (60 to 80 ). The inventory of perceived social support was prepared and adjusted by Davari and Cheraghi (13). This inventory consists of three dimensions of social support: 1) emotional support (questions 1 to 12), 2) informational dimension (questions 13 to 20), and 3) tangible dimension (question 21 to 30). Questions of this inventory were scaled as never (score 1), always (score 4) according to a 4-point Likert scale. Therefore, the obtained score ranged between 30 and 120. The scores obtained for perceived social support were classified in three groups (low, average, high) in such a way that scores between 30 and 59 were specified as low perceived social support, between 60 and 89 as average perceived social support, and between 90 and 120 as high perceived social support. Reliability and validity of state-trait anxiety inventory was verified inside and outside Iran with correlation coefficients of $r=0.93$ and $r=0.89$, respectively (14). Reliability and validity of perceived social support inventory was verified through correlation coefficient $(\mathrm{r}=0.895)$ and 
Cronbach's alpha (87\%) (13). Data were analyzed using descriptive statistics and the Spearman correlation coefficient test along with SPSS software.

\subsection{Data Collection and Research Ethics}

The Research Ethics Committee of the Nursing and Midwifery School of Islamic Azad University, Isfahan Branch (Khorasgan) approved this study. In order to access the subjects, first, three medical centers with hemodialysis ward were selected randomly. Then, the treatment records of all patients under hemodialysis treatment in these three centers were investigated. Then, patients who met the inclusion criteria were selected. Afterwards, the researcher gave some information about the aim of the study and data collection methods to the patients who were in the hemodialysis ward for treatment. A total of 126 patients entered the study after acquiring information about the study and signing a written consent form after being assured about the confidentiality of their information. It is noteworthy that the subjects or the researcher completed the inventory.

\section{Results}

The average age of the participants in this study was $14.51 \pm 53.11$, and $60.3 \%$ of them were males. In addition, $56.3 \%$ of the subjects were illiterate or had only an elementary education. Furthermore, $59.5 \%$ of the subjects reported that their families as low-income, $22.5 \%$ as average and $18 \%$ as high-income families. The majority of subjects received average support (68.3\%). Respectively, 13.5\% (17 subjects) and 18.2\% (23 subjects) of the patients received low and high perceived social support. The level of different aspects of social support is shown in Table 1. The average of social support dimensions are respectively reported as emotional dimension 54.45, information dimension 55.05, and tangible dimension 40.02. Considering the above results, the subjects received lower tangible support compared to other dimensions. Respectively, 65 and $67.5 \%$ of participants suffered from average trait and state anxiety (Table 2). The Spearman correlation coefficient demonstrated that there was an inverse relationship between state and trait anxiety and total perceived social support $(\mathrm{p}<0.01)(\mathrm{r}=-0.229)$ and emotional $(p<0.001)(r=-0.364)$ and informational $(p<0.002)(r=-0.27)$ dimensions. This is while it had no significant relationship with tangible dimension $(\mathrm{p}<0.196)(\mathrm{r}=-0.006)$. Trait anxiety has the highest relation with social support in terms of emotional dimension, while it is significantly related to social support in terms of informational dimension (Table 3).

Table 1. Frequency Distribution of the social support dimensions of the subjects

\begin{tabular}{|l|l|l|l|l|l|l|}
\hline \multirow{2}{*}{ Dimensions } & \multicolumn{4}{|l|}{ Level } & \multicolumn{4}{l|}{ Average } & \multicolumn{2}{l|}{ High } \\
\cline { 2 - 8 } & Low & $\mathrm{n}$ & $\%$ & $\mathrm{n}$ & $\%$ \\
\hline Social Support Dimensions & $\mathrm{n}$ & $\%$ & $\mathrm{n}$ & $\mathbf{6}$ & \\
\hline Emotional Dimension & 18 & 14.3 & 71 & 56.3 & 37 & 29.4 \\
\hline Informational Dimension & 12 & 9.5 & 81 & 64.3 & 33 & 26.2 \\
\hline Tangible Dimension & 39 & 31 & 75 & 59.5 & 12 & 9.5 \\
\hline
\end{tabular}

Table 2. Frequency Distribution of state and trait anxiety levels in the subjects

\begin{tabular}{|l|l|l|l|l|}
\hline \multicolumn{2}{|c|}{ Anxiety } & \multicolumn{2}{l|}{ Level } \\
\cline { 3 - 5 } \multicolumn{2}{|c|}{} & Low & Average & Severe \\
\hline Trait anxiety & $\mathrm{n}$ & 24 & 82 & 20 \\
\cline { 2 - 5 } & $\%$ & 19 & 65 & 16 \\
\hline State anxiety & $\mathrm{n}$ & 23 & 85 & 18 \\
\cline { 2 - 5 } & $\%$ & 18.3 & 67.3 & 14.3 \\
\hline
\end{tabular}

Table 3. Results of Spearman correlation coefficients between the state and trait anxiety levels of perceived social support and its dimensions

\begin{tabular}{|l|l|l|l|l|}
\hline Social Support Dimensions & Trait anxiety level & State anxiety level \\
\cline { 2 - 5 } & Correlation coefficients & $\mathrm{p}$ & Correlation coefficient & $\mathrm{p}$ \\
\hline Social Support Total & -0.229 & 0.01 & -0.340 & 0.001 \\
\hline Emotional Dimension & -0.364 & 0.001 & -.0375 & 0.001 \\
\hline informational Dimension & -.271 & 0.002 & -0.402 & 0.001 \\
\hline Tangible Dimension & -0.006 & 0.196 & -0.162 & 0.066 \\
\hline
\end{tabular}




\section{Discussion}

The current study reported the results of investigating the relationship between perceived social support and anxiety in patients with ESRD under hemodialysis treatment. In this study, over half of the subjects (59.5\%) reported that they were from low-income families. One of main complications of chronic diseases is that the sufferers must retire early because of their disease. Unemployment of these patients results in the reduction of their incomes $(8,15)$. By reducing their incomes, they have to change their lifestyles and habits (15). The results of this study demonstrated that the majority of subjects $(68.3 \%)$ received average social support. The important is sue is that family members and a social network offer more social support when an acute disease occurs. However, this does not happen in chronic diseases (16). In addition, in patients under hemodialysis treatment, having mental perception of the situation could have negative effect on performing their social role (15), which results in the reduction of being understood and receiving social support. Reduction of social support is related to the feeling of hopelessness and loneliness and, finally, their sense of well-being. Obviously, we must remember that hope plays an important role in continuing treatment and sense of well-being (17). However, based on the results of previous studies, social support affects mortality in patients under hemodialysis treatment (18). Considering that social support plays an important role in coping with chronic diseases (9), it should be attempted to increase social support in these patients to increase their ability to cope with this disease and its conditions and, as a result, to reduce mortality and morbidity of patients with chronic renal failure who are taking hemodialysis treatment. According to the results, the subjects received lower tangible support than other dimensions (average 40.02). In previous studies, it was demonstrated that informational and emotional support play an important and significant role in the diagnosis and treatment of chronic diseases (16), in such a way that, in patients receiving higher emotional support, there is a lower possibility of diagnosing hypertension (16). It is noteworthy that hypertension is one of the main risk factors of renal diseases. It should be noted that males are looking for tangible support more than females, while females are inclined to receive emotional support (20). Considering that, in this study, the majority of subjects were seeking tangible support, they had not perceived this dimension of social support.

With regards to the results of this study, it was specified that over half of the participants suffered from an average state and trait anxiety. Based on the results of the study conducted by Cukor et al. (2008), a significant percentage of hemodialysis patients suffer from anxiety and depression (4). Patients under hemodialysis treatment suffer from state anxiety more than patients with other chronic diseases (15). Zahirodin et al. found a direct relationship between hemodialysis and anxiety, in such a way that they believed that hemodialysis causes the occurrence of anxiety in patients (21). In a study by Nazemian et al., more than half of the participants suffered average state and trait anxiety (14). Scientists believe that changing the integrity of tissues with vascular access and changes of life conditions result in anxiety that affects the self-confidence of patients and results in depression and anxiety (21, 15). Since serious problems occur in patients with anxiety and depression, it is important to take this issue into account. These problems affect the family's psychological status and impact the patient's quality of life, rate of attempting suicide and successful suicide, long hospitalization, and even the lifetime of the patient $(4,22)$. However, losing financial resources increases these patients' anxiety about the future (15). The results of this study showed that there is an inverse relationship between state and trait anxiety and perceived social support $(\mathrm{r}=-0.340, \mathrm{r}=-0.229)$. It was stated before that there is a close relationship between state and trait anxiety and social demographic features (23). Researchers believe that perceived social support is effective in reducing economic problems, unemployment, low income, losing job security and health expenditures. In addition, improving social network decreases depression and anxiety of patients and results in health satisfaction and reduction of anxiety (24). Furthermore, offering emotional support plays an important role in increasing performance and coping with stress and improves people's mental and physical health (19). Faraji et al. (25) believed that social support acts as a moderator in anxiety and depression disorders and that there is a negative relationship between social support and anxiety and depression. Considering that social support is a subjective sense of belonging, acceptance and love and being loved, it creates a safe and secure relation the main features of which are sense of intimacy and closeness. Social support is a bilateral assistance that results in creation of positive impression of oneself, self-acceptance, and sense of love and worthiness. These could give the person the opportunity for self-actualization and development. Therefore, when a person receives social support, her or his social anxiety increases significantly because this support acts as a protective shield. However, the lack of support and of a secure relation that is created in the light of other's social support results in the reduction of a positive impression of oneself and provides the background for anxiety (25). Effects of social support and religiousness as the coping method for anxiety indicate that higher social support is correlated with lower anxiety, and the highest effect of religiousness in reducing anxiety is provided through social support, which represents the mediator role of social support (26). Riahi et al. believed that social support is the 
most powerful and most important predictive factor of mental health. In fact, mental health is endangered by the reduction of supportive resources (26).

The remarkable issue is that patients under hemodialysis treatment who suffer from mental problems have their perception of social support affected by this treatment (19). Emotional and information dimensions of social support are inversely related to anxiety $(\mathrm{p}<0.05)$, while the tangible dimension of social support is not significantly related to anxiety $(\mathrm{p}>0.05)$. Patients under hemodialysis treatment with lower education suffer from higher trait anxiety (15). Trait anxiety is highly related to social support in terms of emotional dimension $(\mathrm{r}=0.364)$. Lack of emotional support creates anxiety in the patient more than other dimensions of social support. State anxiety is highly related to social support in terms of informational dimension $(\mathrm{r}=-.402)$. Lack of informational support makes the patient prone to state anxiety. Therefore, to reduce state anxiety, more and detailed information should be provided for the patients. However, it could be stated that lack of awareness about the future increases state anxiety in these patients. Among the limitations of this study, it could be stated that subjects may have not reflected their real feeling when answering the questions. In addition, the current study did not include other dimensions of social support (such as the inductive dimension and self-esteem). Therefore, the results of this study could not be generalized in these aspects.

\section{Conclusions}

The results of this study showed that patients under hemodialysis treatment suffer from average perceived social support and state and trait anxiety. In addition, perceiving emotional and informational support is inversely related to state and trait anxiety. Therefore, hemodialysis affects different aspects of patients' lives including their social and mental dimension, and each one of these life dimensions affects other dimensions as well. This shows the interaction of different dimensions of life. Therefore, it is suggested to pay special attention to other aspects of life, especially mental and social aspects in these patients. Conducting a semi-experimental complementary study on the effects of improving perceived social support on different aspects of life including quality of life and lifestyle in patients under hemodialysis treatment, could be a suitable course for later studies in this field.

\section{Acknowledgments:}

This research project was approved by Islamic Azad University, Isfahan Branch (Khorasgan). All expenditures of the current study were provided by Islamic Azad University, Isfahan Branch. The authors express their thanks and appreciation to the officials of Zahraye Marziye, Hojatiye, and Shariati Hospitals.

\section{Conflict of Interest:}

There is no conflict of interest to be declared.

\section{Authors' contributions:}

All authors contributed to this project and article equally. All authors read and approved the final manuscript.

\section{References}

1) Levey AS, Atkins R, Coresh J, Cohen EP, Collins AJ, Eckardt KU, et al. Chronic kidney disease as a global public health problem: Approaches and initiatives - a position statement from Kidney Disease Improving Global Outcomes. Kidney Int. 2007; 72(3): 247-59. doi: 10.1038/sj.ki.5002343, PMID: 17568785.

2) Schieppati A, Remuzzi G. Chronic renal diseases as a public health problem: Epidemiology, social, and economic implications. Kidney Int Suppl. 2005; (98): S7-S10. doi: 10.1111/j.1523-1755.2005.09801.x, PMID: 16108976.

3) Andrew S. End-Stage Renal Disease and Renal Replacement Therapy in older Patients. Nephrourol Mon. 2012; 4(2): 425-30. doi: 10.5812/numonthly.1825, PMCID: PMC3614263.

4) Cukor D, Coplan J, Brown C, Friedman S, Newville H, Safier M, et al. Anxiety Disorders in Adults Treated by Hemodialysis: A Single-Center Study. Am J Kidney Dis. 2008; 52(1): 128-36. doi: 10.1053/j.ajkd.2008.02.300, PMID: 18440682 .

5) Abdel-Kader K, Unruh ML, Weisbord SD. Burden Symptom, Depression, and Quality of Life in Chronic and End-Stage Kidney Disease. Clin J Am Soc Nephrol. 2009; 4(6): 1057-64. doi: 10.2215/CJN.00430109, PMID: 19423570. 
6) Byers AL, Yaffe K, Covinsky KE, Friedman MB, Bruce ML. High Occurrence of Mood and Anxiety Disorders Among Older Adults The National Comorbidity Survey Replication. Arch gen psychiatry. 2010; 67(5): 489-96. doi: 10.1001/archgenpsychiatry.2010.35, PMID: 20439830.

7) Giang LM. Tighiouart H, Lou KV, Agganis Brian, Drew DA, Shaffi K, et al. Measures of Blood Pressure and Cognition in Dialysis Patients. Hemodial Int. 2013; 17(1): 24-31. doi: 10.1111/j.15424758.2012.00718.x, PMID: 22716218.

8) Callander E, Schofield DJ. The relationship between employment and social participation among Australians with a disabling chronic health condition: a cross-sectional Analysis. BMJ Open. 2013; 3(1). pii: e002054. doi: 10.1136/bmjopen-2012-002054, PMID: 23370010 , PMCID: PMC3563112.

9) Verheijden MW, Bakx JC, Weel Cv, Koelen MA, StaverenWA. Role of social support in lifestyle-focused weight Management interventions. Eur J Clin Nutr. 2005; 59 Suppl 1: S179-86. PMID: 16052189.

10) Chisholm-Burns MA, Sprivey CA, Wilks SE. Factors related to immunosuppressant medication adherence in renal transplant recipients. Clin Transplant. 2010; 24(3): 312-20. doi: 10.1111/j.13990012.2009.01060.x, PMID: 19694770.

11) Kroenke CH, Kwan ML, Neugut AI, Ergas IJ, Wright JD, Caan BJ, et al. Social Networks, Social Support Mechanism, and Quality Of Life After Breast Cancer Diagnosis. Breast Cancer Res Treat. 2013; 139(2): 515-27. doi: 10.1007/s10549-013-2477-2, PMID: 23657404.

12) Abbasi A, Fayyazi S, Ahmadi F, Haghighizade MH. The efficacy of home walking exercise program on functional performance and quality of life in patients with heart failure. J Gorgan Univ Med Sci. 2007; 9(1): 49-54.

13) Davaridolatabadi E, Cheraghi MA. Designation of Special Tools for CHF Patient. In: Tabib A. Editor. 17th Congress of Iranian Heart Association; 2011: Tehran. 2011.

14) Nazemian F, Ghafari F, Poorghaznein T. Evaluation of Depression and Anxiety in Hemodialysis Patients. Med J Mashad Univ Sci. 2008; 51(3): 171-76.

15) Klaric M, Letica I, Petrov B, Tomic M, Klaric B, Letica L, et al. Depression and Anxiety in Patients on Chronic Hemodialysis in University Clinical Hospital Mostar. Coll Antropol. 2009; 33 Suppl 2: 153-8. PMID: 20120532.

16) Cornwell EY, Waite LJ. Social Network Resources and Management of Hypertension. J Health Soc Behav. 2012; 53(2): 215-31. doi: 10.1177/0022146512446832, PMID: 22660826.

17) Pehlivan S, Ovayolu O, Ovayolu N, Sevinc A, Camci C. Relationship between hopelessness, loneliness, and perceived social support from family in Turkish patients with cancer. Support Care Cancer. 2012; 20(4): 733-9. doi: 10.1007/s00520-011-1137-5, PMID: 21461631.

18) Thong MSY, Kaptein AA, Krediet RT, Boeschoten EW, Dekker FW. Nephrol Dial Transplant. 2007; 22(3): 845-50, PMID: 17164318.

19) Cukor D, Cohen SD, Peterson RA, Kimmel PL. Psychosocial Aspects of Chronic Disease: ESRD as a Paradigmatic Illness. J Am Soc Nephrol. 2007; 18(12): 3042-55. PMID: 18003775.

20) Wilson DK, Kliewer W, Bayer L, Jones D, Welleford A, Heiney M, et al. The influence of gender and emotional versus instrumental support on cardiovascular reactivity in African-American adolescents. Ann Behav Med. 1999; 21(3): 235-43. doi: 10.1007/BF02884840, PMID: 10626031.

21) Zahirodin A, Samimi Ardestani S. Anxiety and dialysis. Feyz. 2001; 4(4): 95-8.

22) Malekian A, Alizadeh A, Ahmadzadeh GH. Anxiety and Depression in Cancer Patients. J Res Behav Sci. 2007; 5(2): 115-9.

23) Kohli S, Batra P, Aggarwal HK. Anxiety, locus of control, and coping strategies among end-stage renal disease patients undergoing maintenance hemodialysis. Indian J Nephrol. 2011; 21(3): 177-81. doi: 10.4103/0971-4065.83729, PMID: 21886977, PMCID: PMC3161435.

24) Rambod M, Shabani M, Shokrpoor N, Rafii F, Mohammadaliha J. Quality of life of hemodialysis and renal transplantation patients. Health Care Manag. 2011; 30(1): 23-8. doi: 10.1097/HCM.0b013e3182078ab6, PMID: 21248544.

25) Faraji A, Ariapour S, Abdi A. The role of coping styles and social support in discriminating of students with high and low test anxiety. J Educational Psychology. 2011; 6(19): 47-68.

26) Riahi M, Aliverdinia A, Pourhossein Z. Relationship between Social Support and Mental Health. Social Welfare. 2011; 10(39): 85-121. 